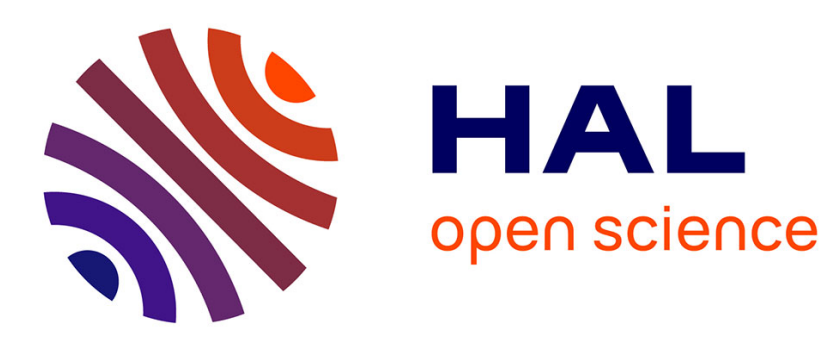

\title{
Diagnosis of Induction Motor Faults Using Instantaneous Frequency Signature Analysis
}

\author{
Abdesselam Lebaroud, Guy Clerc
}

\section{To cite this version:}

Abdesselam Lebaroud, Guy Clerc. Diagnosis of Induction Motor Faults Using Instantaneous Frequency Signature Analysis. ICEM, Sep 2008, Vilamoura, Portugal. 10.1109/ICELMACH.2008.4799993 . hal-00375983

\section{HAL Id: hal-00375983 https://hal.science/hal-00375983}

Submitted on 2 Jan 2019

HAL is a multi-disciplinary open access archive for the deposit and dissemination of scientific research documents, whether they are published or not. The documents may come from teaching and research institutions in France or abroad, or from public or private research centers.
L'archive ouverte pluridisciplinaire HAL, est destinée au dépôt et à la diffusion de documents scientifiques de niveau recherche, publiés ou non, émanant des établissements d'enseignement et de recherche français ou étrangers, des laboratoires publics ou privés. 


\title{
Diagnosis of induction motor faults using instantaneous frequency signature analysis
}

\author{
LEBAROUD, $\mathrm{A}^{1}$, CLERC, $\mathrm{G}^{2}$ \\ (1) LEC, Université de Constantine, Algérie \\ (2) Université de Lyon, Lyon, F-69622, France ; Université Lyon 1, Lyon, F-69622, France ; CNRS, \\ UMR5005, Laboratoire AMPERE, Villeurbanne, F-69622, France \\ lebaroud@yahoo.fr
}

\begin{abstract}
This paper investigates a new technique for diagnosing faults of three-phase induction motors. The Instantaneous Frequency Signature Analysis (IFSA) relates to the monitoring of the fundamental frequency modulation for the diagnosis of faults. The rotor and stator faults in induction machines involve an internal magnetic imbalance, which is reflected in the stator current. This effect may be detected by estimating the fundamental instantaneous frequency signature via stator current. The IFSA is a non-intrusive, on-line monitoring technique for the faults diagnosis.
\end{abstract}

Keywords: Induction Motor, Faults, Instantaneous frequency signature analysis

\section{INTRODUCTION}

Three-phase induction motors are the most widely used electrical machines. In an industrialized nation, they can typically consume between 40 to $50 \%$ of its generated capacity. Consequently, they have to be safe and reliable. However, adverse service conditions may lead to unexpected machinery failure including costly repair as well as extended process downtime. Induction motor behavior during abnormal conditions and their diagnosis have been a challenging topic for many interested researchers. Their major faults can broadly be classified as the following [1]:

- Stator faults resulting in the opening or shorting of one or more of a stator phase windings,

- Abnormal connection of the stator windings,

- Broken rotor bar or cracked rotor end-rings.

- Static and / or dynamic air-gap irregularities,

-Bent shaft (akin to dynamic eccentricity) which may result in a rub between the rotor and stator causing serious damage to stator core and windings.

These faults may produce one or more of the symptoms as given below:

- Unbalanced air-gap voltages and line currents,

- Increased torque pulses,

- Decreased average torque,

- Increased losses and efficiency reduction,

- Excessive heating.

On line fault diagnostics of induction motors are very important to ensure safe operation, timely maintenance, increased operation reliability, and preventive rescue.

In recent years, intensive research $[2,3,4,5,6,7]$ effort has been focused on developing new techniques for monitoring and diagnosing electrical machines. They include:

- Motor current signature analysis (MCSA).
- Time- frequency domain analysis of stator current

- Classification by time-frequency representations of stator currents.

- Temperature measurement.

- Space vector angular fluctuation detection (SVAF).

- Vibration monitoring.

- Diagnosis via pattern recognition, artificial intelligence and neural network.

Of all the above techniques, MCSA seems to be the best possible option. It is non-intrusive and uses the stator winding as search coil. Moreover, it is not affected by the type of load and other asymmetries [4]. However, it presents some limits. Firstly, the ability in identifying faults greatly depends on load. When it is weak, the sidebands become too close to the fundamental frequency to be distinguished. Secondly, the magnitude of the sideband components is considerably smaller than the magnitude of the fundamental component. Thirdly, it has to be used off line because the stator current waveform should be stored in the mass memory of a computer for analysis by a diagnostic algorithm. Both stator and rotor faults are characterized by low frequencies close to the fundamental frequency of $50 \mathrm{~Hz}$. However, this carrier frequency considered awkward for the MCSA becomes interesting by the IFSA technique. More in detail, the stator current, as a sinusoidal signal, contains three components; amplitude, phase and frequency. Grouped, the latter do not permit a better characterization of faults whatsoever in the time domain or frequency, especially for online monitoring of faults. The idea is to separate the three components and monitor instantaneously each component in order to have a signature that characterizes the fault and that lends itself best in the process of monitoring machine. In this article we discussed the characterization of faults by the instantaneous amplitude and instantaneous frequency (IFSA technique). The latter is more detailed, view of the relevance of its time representation, its progressive depending on the severity of the fault and its low sensitivity towards the levels of charge. However, the IFSA technique relates to the monitoring of the fundamental frequency modulation for the diagnosis of both stator and rotor faults. It essentially needs a sensor for measuring the stator current, and a data-acquisition system for acquiring the signal waveform. Induction motor faults. 


\section{THEORY OF STATOR AND ROTOR FAULTS}

\section{A. ROTOR FAULT}

Due to arduous duty cycles [8,9], broken rotor bars may constitute a serious problem with certain induction motors. Although broken rotor bars do not initially cause an induction motor to fail, they may have serious secondary effects. The fault mechanism can result in broken parts of the bar hitting the end winding of a high voltage motor at high velocity. As a consequence, serious mechanical damage to the insulation and a winding failure can follow, resulting in a costly repair and lost production. A fault on the rotor such as broken bars introduces asymmetrical working conditions. The current rotor bars which are at the frequency $(s f)$ can be expressed into positive and negative sequence components $( \pm \mathrm{s} f)[10]$ within the rotor, where $\mathrm{s}$ is the slip. Consequently, the negative sequence rotor current results in stator currents at frequency (fig.1).

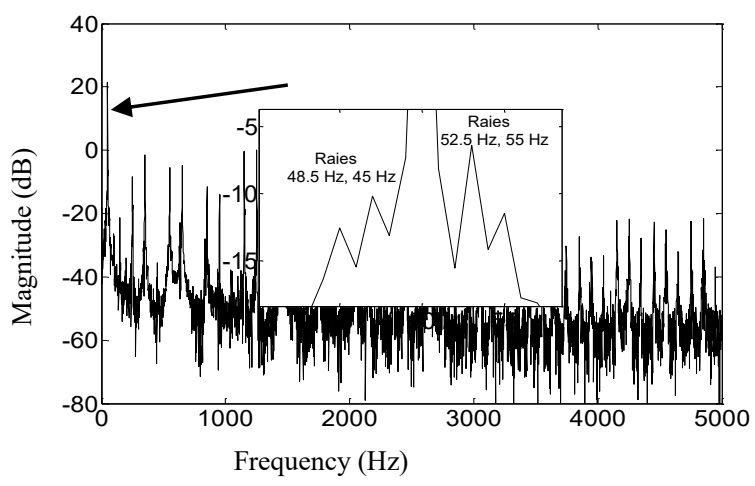

Fig.1. Example of spectrum of current vector with three broken bars

$$
-s f+f_{r}=-s f+f-s f=(1-2 s) f
$$

The interaction of the $(1-2 s) f$ harmonic of the motor current with the fundamental air-gap flux produces speed ripple at $2 s f$ and gives rise to additional motor current harmonics at frequencies $(1 \pm 2 k s) f, k=1,2,3$.. [11]

The motor-load inertia also affects the magnitude of these sidebands. Other spectral components may be observed in the stator line current [12].

$$
(k / p(1-s) \pm s) f \quad k / p=1,3,5 \ldots
$$

\section{B. Stator fault}

In ideal conditions, the motor supply current contains only a positive-sequence component. In case of stator fault such as, inter-turn short circuit in the motor stator winding, the supply current will manifest of unbalance, the stator asymmetry produces a component at frequency- $f$ (i.e. a negative sequence component) giving rise to torque ripples at frequencies of $2 s f$ and consequently producing speed ripples of different amplitude, being differently filtered by the machine-load inertia. The spectral analysis of the stator current is an effective tool, which is able to define all the frequencies, particularly those related to the fault. The spectrum of the phase current does not permit having the negative component of the current. However, the spectral analysis of the stator current space vector allows the separation of two sequences from spectra (Fig. 2). The positive sequence is defined in the domain $\left[0, f_{\max }\right]$ while the negative one is defined in the domain $\left[-f_{\max }, 0\right]$. However, the frequency of the unbalance stator is located at $2 f$ of fundamental $(f)$.

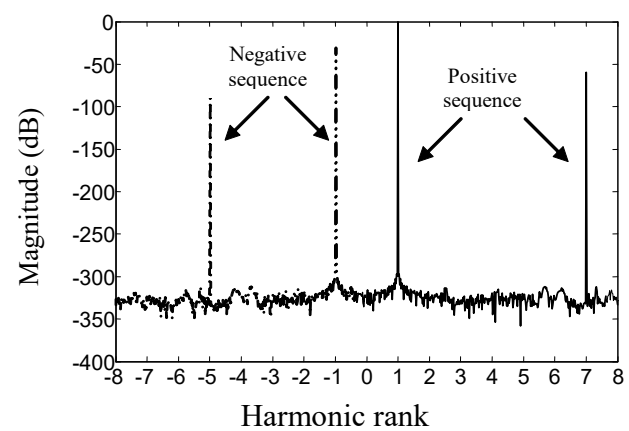

Fig.2. Example of unbalanced currents space vector spectrum

\section{DETECTION OF FAULTS BY INSTANTANEOUS AMPLITUDE}

\section{A. Principle}

The stator current of phase a of induction motor can be developed in a Fourier series:

$$
i_{a}(t)=\sum_{k} \sqrt{2} I_{a k} \sin \left(k \omega t+\varphi_{a k}\right)
$$

Where $k=1,2, \ldots$ is the order of harmonic components and $I_{a k}, k \omega, \varphi_{a k}$ are the RMS value, angular frequency and phase angle of the $\mathrm{k}^{\text {th }}$ harmonic component, respectively.

Numerical expression of (3) is:

$$
i_{a}(m)=\sum_{k=1}^{k_{M}} \sqrt{2} I_{a k} \sin \left(k \omega m \Delta t+\varphi_{a k}\right)
$$

Where $k_{M}$ is the order of the harmonic component having the maximum frequency after filtering.

Given a real signal (4), the instantaneous amplitude is the module of Hilbert transformed of the signal considered. Since the signal is broadband and contains harmonics from various sources (pollution source or harmonics generated by the machine itself), we remove unwanted harmonics by filtering the current signal by a low pass filter with cutoff frequency of $100 \mathrm{~Hz}$. The principle of instantaneous amplitude is illustrated in Figure 3. 


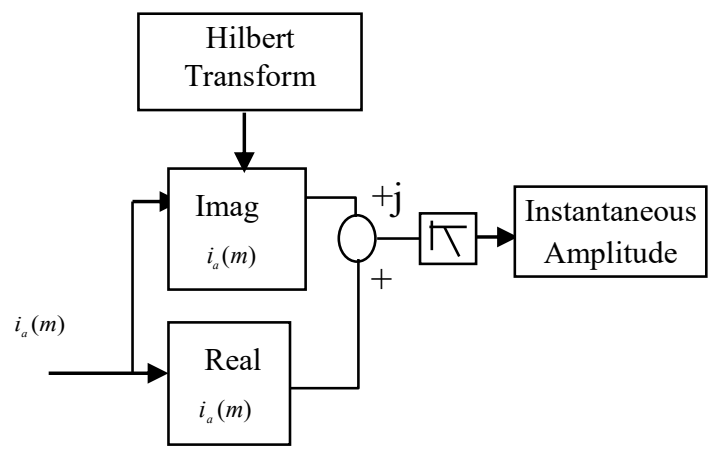

Fig. 3. Principe de l'amplitude Instantanée

\section{IV.INSTANTANEOUS FREQUENCY SIGNATURE ANALYSIS (IFSA)}

The instantaneous frequency $f(t)$ uses the concept of the instantaneous phase of the signal and is defined as the derivative of the phase $\varphi(t)$ figure (4) $[13,14,15]$.

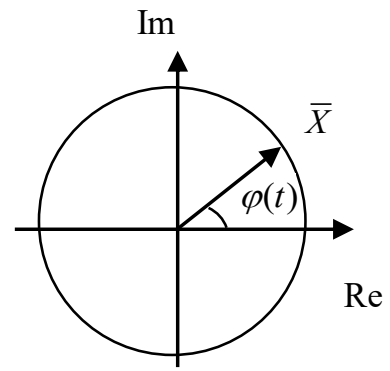

Fig. 4. Instantaneous phase of real signal

$$
f_{i}=\frac{1}{2 \pi} \frac{d \varphi(t)}{d t}
$$

Where $f_{i}$ in Hertz

Obtaining the phase $\varphi(t)$ from a real signal $x(t)$, one would have to associate the signal $y(t)$ determined by the Hilbert transform leading to the complex form:

$$
x(t)+j y(t)
$$

The phase $\varphi$ being defined as the arctangent between y (t) and $x(t)$, the frequency is expressed as:

$$
f_{i}=\frac{1}{2 \pi} \frac{d}{d t} \arctan \left(\frac{y}{x}\right)=\frac{1}{2 \pi} \frac{x y^{\prime}-y x^{\prime}}{x^{2}+y^{2}}
$$

Where: $x^{\prime}=d x / d t$

The instantaneous symmetrical component of stator currents is given by:

$$
i(t)=\frac{\sqrt{2}}{3}\left(i_{a}(t)+a i_{b}(t)+a^{2} i_{c}(t)\right)
$$

The instantaneous symmetrical component $i(t)$ gives the real and imaginary components of the stator currents. It leads to acquiring samples of two currents to calculate:

$\operatorname{Re} i(m)=\sqrt{\frac{2}{3}} i_{a}(m \Delta t)-\frac{1}{\sqrt{6}} i_{b}(m \Delta t)-\frac{1}{\sqrt{6}} i_{c}(m \Delta t)$

$\operatorname{Im} i(m)=\frac{1}{\sqrt{2}} i_{b}(m \Delta t)-\frac{1}{\sqrt{2}} i_{c}(m \Delta t)$

With: $m=0,1,2 \ldots$

If the currents are sampled periodically so that the angle between two moments of sampling $\Delta \varphi$ is weak, we can obtain the instantaneous frequency of the instantaneous symmetrical component figure (5) as:

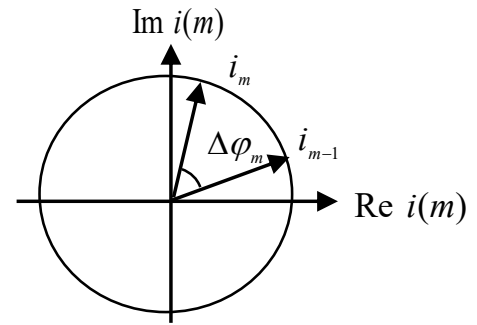

Fig.5. Instantaneous frequency of instantaneous symmetrical component

$$
\begin{aligned}
& \Delta \varphi \cong \sin \left(\varphi_{m}-\varphi_{m-1}\right) \\
& \Delta \varphi \cong \sin \varphi_{m} \cos \varphi_{m-1}-\sin \varphi_{m-1} \cos \varphi_{m}
\end{aligned}
$$

According to the equations (9) and (10) and for a balanced three-phase system, we can write:

$$
\begin{aligned}
& \operatorname{Re} i(m)=i_{m} \cos \left(\varphi_{m}\right) \\
& \operatorname{Im} i(m)=i_{m} \sin \left(\varphi_{m}\right)
\end{aligned}
$$

The instantaneous symmetrical component along the axis $\alpha$ and $\beta$ are then expressed as:

$$
\begin{aligned}
& i_{\alpha m}=\operatorname{Re} i(m) \\
& i_{\beta m}=\operatorname{Im} i(m) \\
& i_{m}=\sqrt{i_{\alpha m}^{2}+i_{\beta m}^{2}}
\end{aligned}
$$

This allows rewriting the equation (7) by: 


$$
\left.f_{i}=\frac{1}{2 \pi T} \frac{1}{i_{m} i_{m-1}}\left(i_{\beta m} i_{\alpha m-1}-i_{\beta m-1} i_{\alpha m}\right)\right)
$$

\section{EXPERIMENTAL INVESTIGATION}

The experimental bench consists of a three-phase asynchronous motor squirrel cage Leroy Somer LS 132S, IP 55, Class $\mathrm{F}, \mathrm{T}^{\circ} \mathrm{C}$ standard $=40^{\circ} \mathrm{C}$. The motor is loaded by a powder brake. Its maximum torque $(100 \mathrm{Nm})$ is reached at rated speed. This brake is sized to dissipate a maximum power of $5 \mathrm{~kW}$. The figure 6 shows the motor bench. For the rotor fault, the bar has been broken by drilling bar of cage squirrel (Fig.7). Simulation of imbalance stator is obtained with a variable autotransformers placed on a phase of the network (Fig.6). An acquisition of current signals was carried out on a test bench; the sampling rate is $10 \mathrm{KHz}$. The motor is supplied in the first case by the network and in the second case by an inverter. The stator currents of the machine are acquired during steady condition on three cases: healthy motor, stator imbalance, and broken bars.

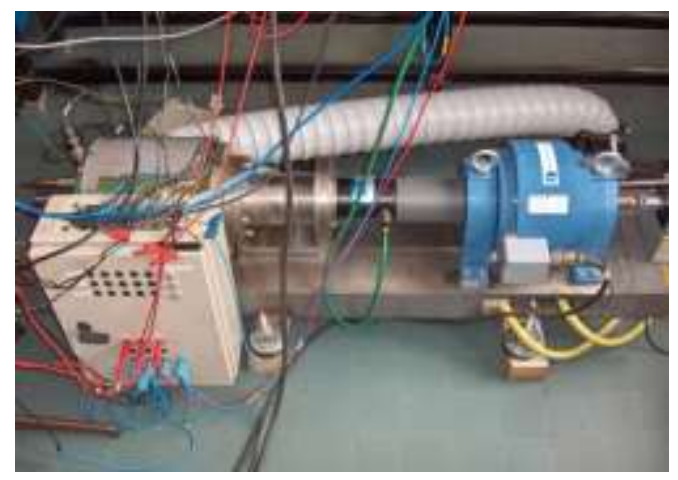

Fig.6. Test bench of induction motor

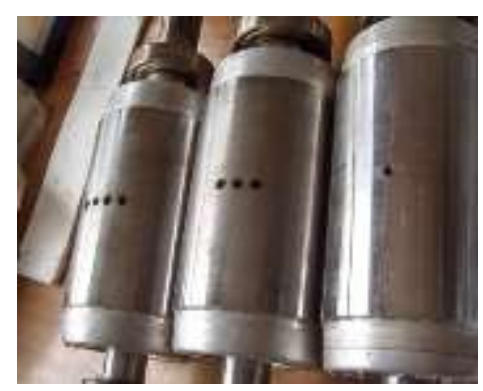

Fig.7. Broken bars

\section{A. Results of instantaneous amplitude}

This technique is applied on stator current (Fig.8) of induction machine supplied by an inverter. The machine presents three broken bars in the rotor.

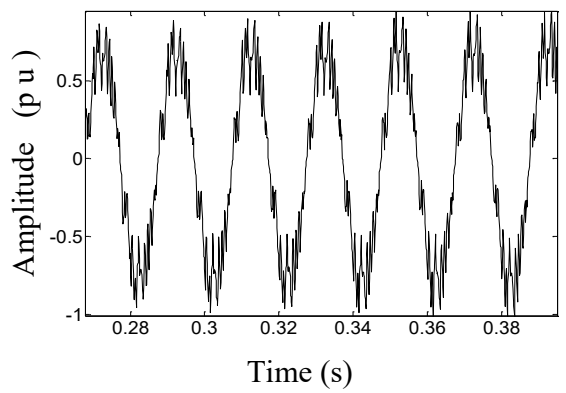

Fig.8. Current stator of a motor fed by an inverter with three broken rotor bars

Figure 9 shows instantaneous amplitude of two stator currents; one healthy (discontinued line) and one with fault (solid line). It is clear that the instantaneous amplitude takes into account the oscillating part of $1 / 2 s f$ period, which holds useful information. In addition, the fundamental component is eliminated, making the form of instantaneous amplitude more readable. The spectrum of the instantaneous amplitude (Fig. 10) illustrates an index of diagnosis very interesting lowfrequency $11 \mathrm{~Hz}$.

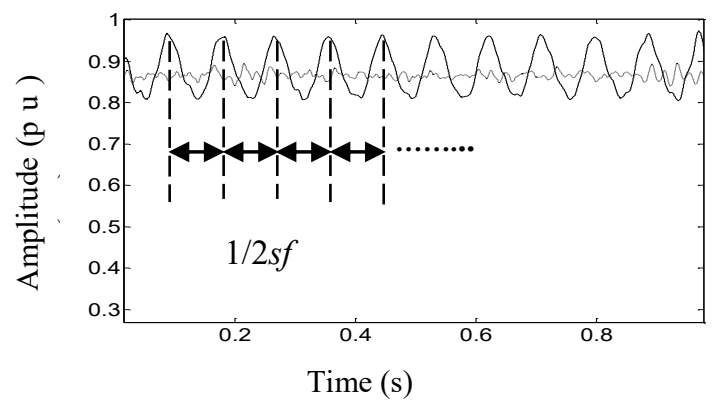

Fig.9. Instantaneous amplitude of the current stator with three broken bars (solid line), current healthy (discontinued line)

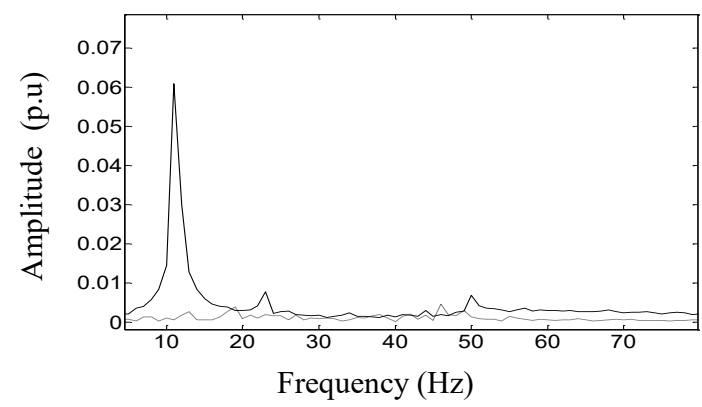

Fig.10. Spectrum of instantaneously amplitude of current; three broken bars (solid line), current healthy (discontinued line)

B. Results of instantaneous amplitude

Figure (11) shows the stator current of motor supplied by the inverter in healthy condition. A deformation of the signal waveform caused an important fluctuation of the instantaneous 
frequency between $-500 \mathrm{~Hz}$ and $500 \mathrm{~Hz}$. thus impossible to extract useful information.
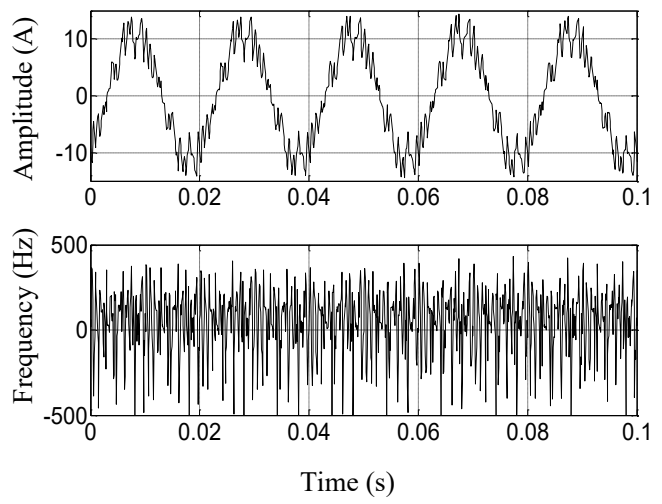

Fig.11. Stator current (top) and instantaneous frequency (inverter supply)

(bottom)

Figure (12) shows the stator current of healthy motor supplied by the network. We can see slight deformation of the signal waveform causing a strong fluctuation of the instantaneous frequency between $25 \mathrm{~Hz}$ and $75 \mathrm{~Hz}$. However the IFSA waveform is inappropriate for the detection and diagnosis.
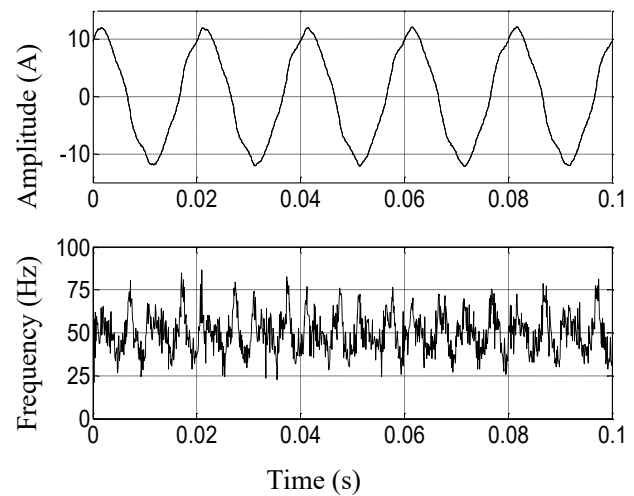

Fig.12. Stator current (top) and instantaneous frequency (network supply) (bottom)

Knowing that the characteristic frequencies of stator fault and rotor fault are located near the fundamental frequency 50 $\mathrm{Hz}$. We have considered only the low frequencies $2 s f$ and $2 f$. Where $2 s f$ frequency is index of rotor fault; $2 f$ frequency is index of stator imbalance. In order to preserve relevant information, the original signal is resampled with a downsampling rate of 50. Only the range of the required frequencies is preserved. By down sampling, the signal dimension is greatly reduced. Electrical noise is also attenuated. A new 200-point signal, that keeps the original signal, is thus obtained.
Figure (13) shows the instantaneous frequency of stator current of healthy motor supplied by inverter. We can notice that the distortion of current waveform is attenuated. It is reflected through an attenuation of the fluctuations of the instantaneous Frequency.
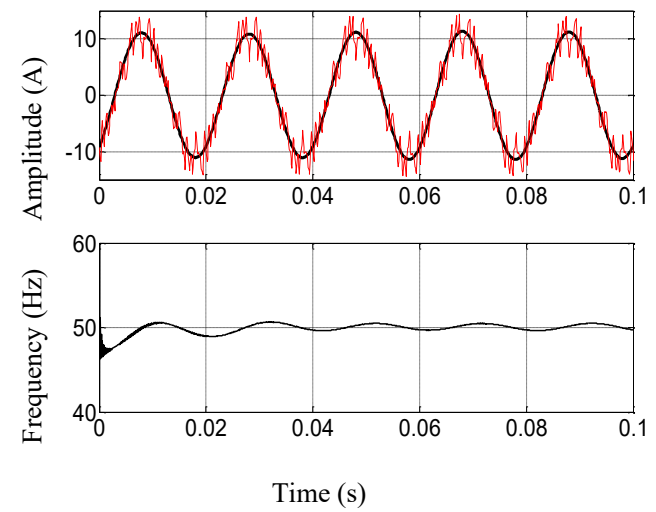

Fig.13. Stator current (top) and instantaneous frequency (inverter supply) (bottom)

Figure (14) represents the instantaneous frequency in the case of three broken bars of the motor supplied by inverter. The amplitude modulation of the stator current appears through equidistant wraps of a duration corresponding exactly to $1 / 2 f s=0.36$ second

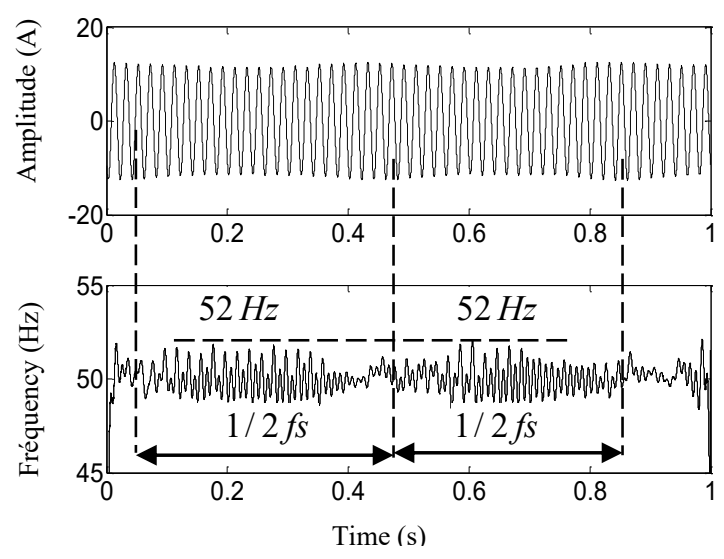

Fig.14. Stator current (top) and instantaneous frequency (inverter supply) (bottom)

The magnitude of Instantaneous Frequency Maximum (IFM) $52 \mathrm{~Hz}$ informs on the severity of the rotor fault (number of broken bar).

The instantaneous frequency of the instantaneous symmetrical component (real and imaginary) in the case of imbalance stator of motor supplied by inverter is represented in Figure (15). The instantaneous frequency is characterized by a number of equidistant peaks regularly spaced with duration $1 / 2 f=0,01$ second. However, we can conclude that 
each fault is characterized in the instantaneous frequency by a specific signature.
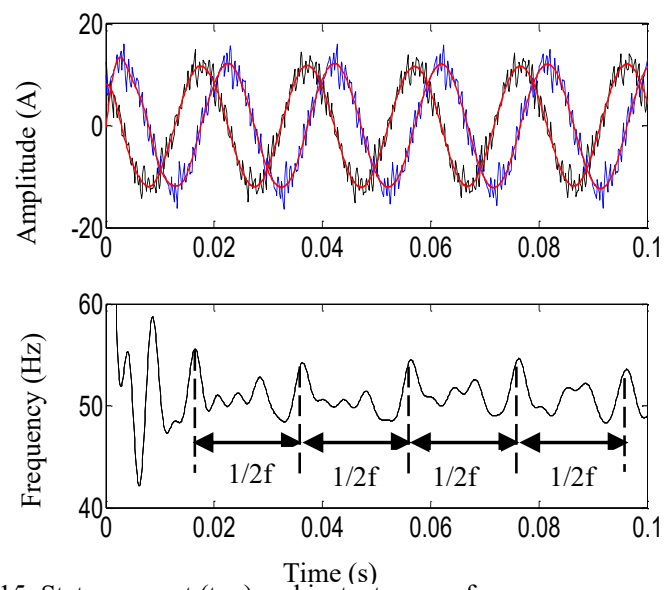

Fig.15. Stator current (top) and instantaneous frequency

(inverter supply) (bottom)

The modulation effects of instantaneous frequency induced by both stator and rotor faults are summarized in table 1 .

\begin{tabular}{|c|c|c|c|}
\hline & $\begin{array}{c}\text { IFSA } \\
\text { index }\end{array}$ & $\begin{array}{c}\text { Magnitude } \\
(\mathrm{Hz})\end{array}$ & $\begin{array}{c}\text { Time (T) } \\
(\text { Second) }\end{array}$ \\
\hline Stator fault & $1 / 2 f$ & 53 & 0.01 \\
\hline Rotor fault & $1 / 2 f s$ & 52 & 0.36 \\
\hline
\end{tabular}

Table.1 Stator and rotor faults by IFSA

In figure (16) the $3 \mathrm{D}$ representation shows clearly that the values of the IFM are significant since the surface has no singularities. Values IFM increases slightly with increasing of both the number of broken bars and the load level. However we can say that the sensitivity of IFSA is accurate to detect one broken bar without load.

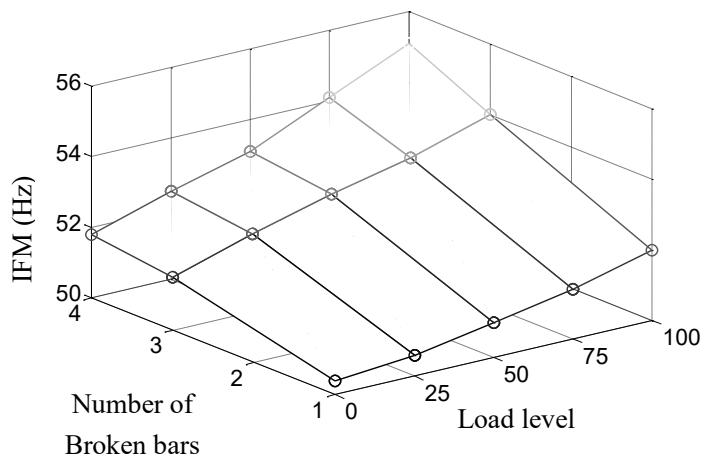

Fig.16. Evolution of IFM with the load level and the number of broken bars

The 3D representation (fig.17) shows that values of stator imbalance IFM are significant because the surface has no singularities. Value IFM increases when level of stator Imbalance increases but it changes slightly with load level.
The sensitivity of the IFM is accurate enough to detect a level of imbalance as low as $2 \%$.

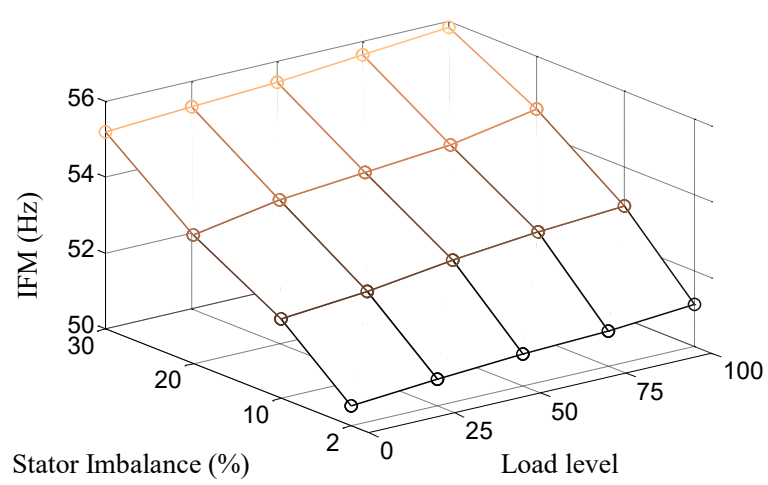

Fig. 17. Evolution of IFM with load level and number of broken bars

\section{CONCLUSION}

The instantaneous frequency presents of reliable indices of diagnosis. The signatures are specific to each type of fault. The re-sampling of original signal with a down-sampling rate 50 has allowed the smoothing of instantaneous frequency and removed the frequencies unnecessary induced by network or inverter thus preserving relevant information and reduce calculation. The fundamental frequency modulation is interpretable at naked eye. The instantaneous frequency maximum is a reliable index which informs on the fault severity.

\section{REFERENCES}

[1] Vas P., Parameter estimation, condition monitoring, and diagnosis of electrical machines. Clarendon Press, Oxford, 1993.

[2] Bellini, A. Filippetti, F. Tassoni, C. Capolino, G.-A. , "Advances in Diagnostic Techniques for Induction Machines", IEEE Industrial Electronics Transactions, V.55, No.12, pp 4109-4126, Dec. 2008.

[3] Kilman G.B., Koegl R.A., Stein J., Endicott R.D., and Madden M.W., Noninvasive detection of broken rotor bars in operating induction motors. IEEE Trans. Energy Conv. Pp. 873-879, 1988.

[4] Kilman G.B. and Stein J., Methods of motor current signature analysis. Electr. Mach. \& Power Syst, Vol. 5, $\mathrm{n}^{\circ}$ 1, pp41-52, 1999.

[5] Ondel O., Boutleux E., Clerc G., " A method to detect broken bars in induction machine using pattern recognition techniques ", IEEE Transactions on Industrial Application Society (IEEE, IAS), Vol. 42, n4, pp.916923, July/August 2006.

[6] Lebaroud Abdesselam, Clerc Guy, " Classification of Induction Machine Faults by Optimal Time-Frequency 
Representations" IEEE Industrial Electronics Transactions, V.55, No.12, pp 4290-4298, Dec. 2008.

[7] Lebaroud Abdesselam, Abdelmalek Khezzar , Ammar Bentounsi , Guy Clerc "Comparison of the Induction Motors Stator Fault Monitoring Methods Based on Current Negative Symmetrical Component", European power electronics and drives (EPE) Journal, $\square \square$ Vol. 1, $\square \square$ no 1 March 2007.

[8] Thomson W. T., M Fenger "Current signature analysis to detect inductions motor faults " Introduction" IEEE Industry Applications Magazine_July/August 2001

[9] Zhongming Y., Wu B.,Sadeghian A., "Current Signature Analysis of Induction Motor Mechanical Faults by Wavelet Packet Decomposition" IEEE transactions on industrial electronics, VOL. 50, NO. 6, December 2003.

[10] Cardoso A.J.M.,. Cruz S.M.A, Carvalho J.F.S., and Saraiva E.S., Rotor cage fault diagnosis in induction motors by park's vector approach. IEEE, IAS'95 Orlando, Florida, pp642-646, Oct 1995.

[11] Filipetti F., Franceschini G.,. Tassoni C, and Vas P., " AI techniques in induction machine diagnosis including the speed ripple effect," vol 1, IEEE IAS, California 1996, pp 655-662,

[12] Thomson W.T. and Stewart I.D., On-line current monitoring for fault diagnosis in inverter fed induction motors. IEE Third international conference on power electronics and drives, London, 1988.

[13] Moore P. J, "Frequency relaying based on instantaneous frequency measurement, IEEE, Transaction on power delivery, vol. 11, No. 4, 1996

[14] Alfonso C, Carlos M, "Instrument for the measurement of the Instantaneous frequency" IEEE, Transaction on instrumentation and Measurement, vol. 49, No. 4, 2000.

[15] Eckhardt V., "Dynamic measuring of frequency and frequency oscillations in multiphase power systems" IEEE Transaction on power delivery, vol. 4, No. 1, 1989. 